\title{
Comparison of impedance cardiography and dye dilution method for measuring cardiac output
}

\author{
W Spiering, P N van Es, P W de Leeuw
}

\begin{abstract}
Objective-To assess the degree of agreement between impedance cardiography, using the NCCOM3-R7 device, and the gold standard-the dye dilution methodboth under basal conditions and after stimulation of cardiac output.

Patients-35 paired measurements in five healthy male volunteers.

Interventions-To obtain higher levels of cardiac output, cardiac performance was stimulated with a dopamine infusion.

Results-In 35 paired measurements, the mean of all the impedance values was higher than that of the dye dilution values, at $10.2 v 7.41 / \mathrm{min}(\mathrm{p}<0.0001)$. The mean discrepancy between the two methods was $3.3 \mathrm{l} / \mathrm{min}$, and the mean bias $-2.9 \mathrm{1} / \mathrm{min}$, with limits of agreement of $\mathbf{- 9 . 0}$ and $\mathbf{3 . 2}$ $1 /$ min. A change in cardiac output could not adequately be predicted by the NCCOM3-R7. In 20 of 25 measurements obtained during continuous intravenous dopamine infusions there was a rise in dye dilution cardiac output (range 0.2 to 5.9 $1 / \mathrm{min})$. Neither the magnitude nor the direction of the change in dye dilution values corresponded with the change measured by impedance cardiography. The mean discrepancy here between the two methods was $1.8 \mathrm{1} / \mathrm{min}$, and the mean bias $\mathbf{- 0 . 8} \mathbf{1} / \mathrm{min}$, with limits of agreement of -4.9 and $3.3 \mathrm{l} / \mathrm{min}$.
\end{abstract}

Conclusions-In healthy volunteers, impedance cardiography with NCCOM3-R7 is inadequate for assessing cardiac output when compared with the dye dilution method.

(Heart 1998;79:437-441)

Keywords: cardiac output; impedance cardiography; dye dilution

An accurate and reliable technique for measuring cardiac output would be of considerable value both in research and in clinical medicine. Ideally, such a technique should be noninvasive, versatile, reliable, cost-effective, and easy to use. ${ }^{1}$ The gold standard for measuring cardiac output still is the dye dilution method. Disadvantages of this method are its invasive character and the impossibility of measuring beat to beat changes.

A popular non-invasive technique that is often used nowadays is the impedance cardiography. Kubicek et al were the first to develop this technique for practical use. ${ }^{2}$ According to these investigators, stroke volume (SV) can be determined by the equation:

$\mathrm{SV}=\mathrm{r} \cdot\left(\mathrm{L}^{2} / \mathrm{Z}_{0}^{2}\right) \cdot(\mathrm{d} Z / \mathrm{d} t)_{\max } \cdot \mathrm{LVET}$, where $\mathrm{r}$ is the resistivity of blood, $\mathrm{L}$ is the distance between recording electrodes, $Z_{0}$ is baseline impedance between the recording electrodes, $(\mathrm{d} Z / \mathrm{d} t)_{\max }$ is the maximum absolute rate of change in the impedance signal for a given beat, and LVET is left ventricular ejection time. Compared with dye dilution cardiac output measurements, White et al reported a small mean difference of $0.1 \mathrm{l} / \mathrm{min}$ between the two methods. ${ }^{3}$ Sramek et al proposed an alternative equation, modelling the thorax as a truncated cone rather than a cylinder. ${ }^{4}$ This equation was later modified by Bernstein. ${ }^{5}$ This SramekBernstein equation is implemented in the now commonly used non-invasive continuous cardiac output monitor (NCCOM3). This device has been compared with thermodilution, ${ }^{6-32}$ the Fick method, ${ }^{22} 26{ }^{34}{ }^{34}$ Kubicek's impedance cardiography, ${ }^{14}{ }^{35}$ and Doppler echocardiography, ${ }^{18} 3637$ in ICU patients, ${ }^{6-8} 1014162024$ 29-31 neonates and children, ${ }^{15} 3337$ healthy subjects, ${ }^{1429343538}$ neurological patients, ${ }^{11}$ surgical patients, ${ }^{12}$ pregnant women, ${ }^{13} 17$ and cardiovascular (including post-CABG) patients. ${ }^{9} 182123252728$ Only two comparative studies with the dye dilution method have been performed, one in children ${ }^{39}$ and one in adult healthy subjects. ${ }^{29}$ Both studies used the previous version of the NCCOM3-R7. Moreover, Thomas used the less reliable, non-invasive, earpiece densitometer for measuring the dye $^{29}$ instead of sampling blood through a peripheral arterial catheter. ${ }^{40}$ The objective of our study, therefore, was to assess the degree of agreement between impedance cardiography and the dye dilution method using arterial sampling. Because most data concerning the correlation or agreement between the two methods have dealt with cardiac output values in the physiological range, we were also interested to explore the agreement at higher cardiac output levels. Thus the second objective of our study was to investigate whether the NCCOM3-R7 device can identify a change in cardiac output in the same way as the dye dilution method.

\section{Methods}

SUBJECTS

Seven healthy male volunteers (mean (SD) age 22 (1.7) years) participated in the study. Two had to be excluded because the central venous catheter could not be adequately positioned in the superior caval vein. The nature and risks of the study were explained to each subject and informed consent was obtained from all. This study had prior approval of the medical ethics committee of the University Hospital Maastricht. 
Table 1 Characteristics of subjects

\begin{tabular}{llllllr}
\hline Subject & $\begin{array}{l}\text { BMI } \\
\left(\mathrm{kg} / \mathrm{m}^{2}\right)\end{array}$ & $\begin{array}{l}\text { Blood pressure } \\
(\mathrm{mm} \mathrm{Hg})\end{array}$ & $\begin{array}{l}\text { Heart rate } \\
\text { (beats/min) }\end{array}$ & $n$ & $\begin{array}{l}\text { Cardiac output } \\
\text { (l/min) }\end{array}$ & \multicolumn{1}{r}{} \\
\hline 1 & 24.8 & $130 / 75$ & 75 & 6 & 6.8 to 11.5 & 0.54 \\
2 & 26.3 & $130 / 60$ & 55 & 8 & 5.1 to 11.1 & 0.68 \\
3 & 24.6 & $135 / 75$ & 50 & 8 & 5.2 to 7.4 & 0.81 \\
4 & 18.6 & $160 / 80$ & 80 & 5 & 5.9 to 10.6 & 0.73 \\
5 & 18.0 & $150 / 70$ & 75 & 8 & 5.7 to 7.5 & -0.01 \\
\hline
\end{tabular}

^Dye dilution ranges.

BMI, body mass index; $\mathrm{n}$, number of paired measurements; $r$, Pearson's correlation coefficient for the relation between dye dilution and impedance $\mathrm{CO}$ measurements.

PROTOCOL

In all subjects cardiac output was measured simultaneously by the dye dilution and the impedance technique. Three to five impedance cardiac output measurements were averaged during the period of dye dilution cardiac output measurement ( \pm 50 seconds). First, after a steady state period of 15 minutes, basal cardiac output values were measured in duplicate. After these basal measurements, each subject received an intravenous infusion of dopamine $(2-6 \mu \mathrm{g} / \mathrm{kg} / \mathrm{min})$ to obtain higher cardiac output values.

\section{CARDIAC OUTPUT MEASUREMENTS \\ Impedance cardiography}

Impedance measurements were obtained with the non-invasive continuous cardiac output monitor model 3, revision 7 (NCCOM3-R7, BoMed Instruments, Irvine, California, USA). This method, which uses changes in transthoracic impedance during cardiac ejection to calculate stroke volume, is described in detail elsewhere. ${ }^{5}$ In brief, a small sinusoidal current is applied to four electrodes at the base of the neck and inferior aspect of the thorax. A set of four electrodes $5 \mathrm{~cm}$ inside the stimulating electrodes record the changing impedance over that area of the thorax. Cardiac output is calculated from the following relation: $\mathrm{SV}=\mathrm{V}_{\mathrm{EPT}} \cdot \mathrm{t}_{\mathrm{LVE}} \cdot(\mathrm{d} Z / \mathrm{d} t)_{\max } / \mathrm{Z}_{0}$, where $\mathrm{SV}=$ stroke volume, $\mathrm{V}_{\mathrm{EPT}}=$ volume of electrically participating tissue calculated from height and weight, $t_{\mathrm{LVE}}=$ left ventricular ejection time, $(\mathrm{d} Z / \mathrm{d} t)_{\max }=$ maximum rate of impedance change during systolic upstroke, and $\mathrm{Z}_{0}=$ baseline thoracic impedance. This method is known as the Sramek-Bernstein method. We used self adhesive electrodes supplied by the manufacturer of the NCCOM3-R7 and positioned them as described. The impedance monitor was set to display cardiac index readings as an average of 16 cardiac cycles. All cardiac index values were transformed afterwards into cardiac output values by multiplying them by with the body surface area of the subjects. In our hands, the variation of repeated impedance measurements was $5 \%$.

\section{Dye dilution method}

The principle of dye dilution cardiac output measurement is to inject rapidly a known quantity of dye at one site into the circulatory system and withdraw blood at a distal site for determination of concentration of dye. ${ }^{40}$ Flow Q (= cardiac output) is calculated from: $\mathrm{Q}=\mathrm{m} /\left(\mathrm{c}_{\mathrm{A}} \cdot \mathrm{t}\right)$, where $\mathrm{m}=$ amount of dye injected, $c_{A}=$ mean concentration of dye, and $\mathrm{t}=$ time of concentration curve. As dye we used indocyanine green (Cardio-Green ${ }^{\mathbb{B}}$ ) that we injected in a bolus $(5.0 \mathrm{mg}$; prepared by the manufacturer) through a central venous catheter into the superior caval vein. At the same time arterial blood from the left brachial artery was withdrawn at a fixed rate $(37.8 \mathrm{ml} / \mathrm{min})$ by a syringe pump and passed through a cuvette with photoelectric cells to record the dye concentration. When blood with dye passes these cells a typical dye concentration curve is produced by the Nihon Kohden MLC- 4200 cardiac output computer. The computer replots the curves in a semilogarithmic manner and then calculates the area under the curve which represents the actual cardiac output. Dye concentration curves were manually checked for accuracy. The agreement between manual and automated measurements in our hands was $98 \%$. Before each cardiac output measurement the apparatus was calibrated. In earlier reproducibility studies we found the variation of repeated determinations to be within $8 \% .^{41}$ The position of the central venous catheter had been checked by $x$ ray before measurements started.

\section{STATISTICAL METHODS}

To express the correlation between impedance and dye dilution cardiac output measurements Pearson's correlation coefficient was calculated. The difference between average impedance cardiac output values and dye dilution cardiac output was tested with the paired $t$ test. The agreement between impedance cardiac output values and dye dilution cardiac output was assessed by calculating the mean bias, its standard deviation, and the $95 \%$ confidence limits of agreement, as described by Bland and Altman. ${ }^{42}$ The mean discrepancy was calculated as $(\Sigma \vee$ [dye dilution - impedance cardiography $\left.]^{2}\right) / n$. Changes in cardiac output were calculated as the difference between cardiac output values under continuous intravenous dopamine infusion and the mean baseline value.

\section{Results}

Body mass index, as well as basal blood pressures and heart rates, are given in table 1 . For each subject, the number of paired cardiac output measurements, ranges in cardiac output, and Pearson's correlation coefficients are also shown in table 1 . In the five subjects a total of 35 paired cardiac output measurements was obtained: 10 under basal conditions and 25 under continuous intravenous dopamine infusion. Blood pressure did not change under dopamine infusion. Heart rate tended to increase, but changes were not statistically significant.

\section{BASAL CARDIAC OUTPUT VALUES}

The Pearson's correlation coefficient of all 10 paired basal measurements combined was 0.11 . When all basal cardiac output values from each subject were averaged, the mean (SD) basal cardiac output was $6.3(0.8) 1 / \mathrm{min}$ for dye dilution and 8.8 (3.2) $1 / \mathrm{min}$ for impedance measurements $(p=0.16)$. In four cases 


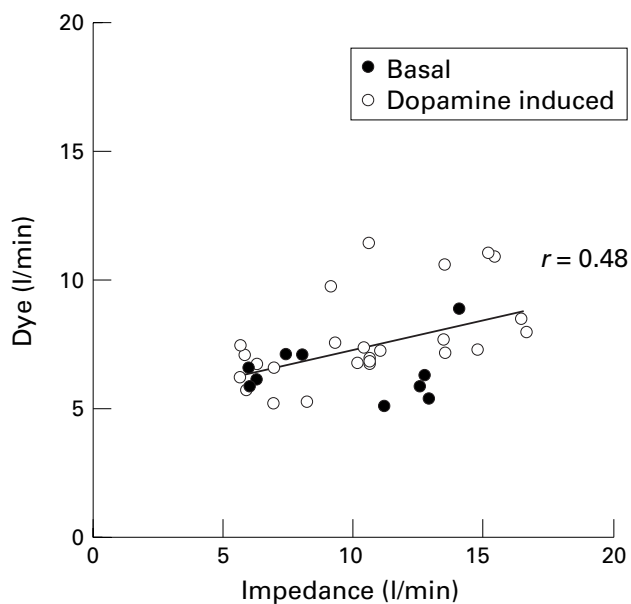

Figure 1 All paired measurements $(n=35)$ : Pearson's correlation coefficient.

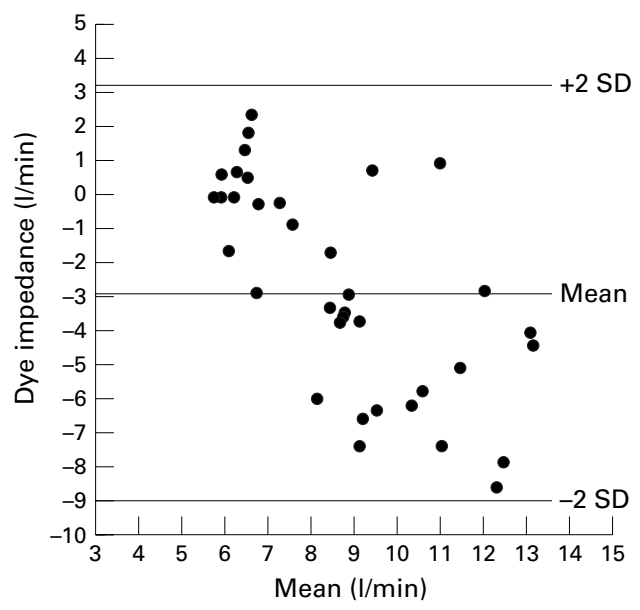

Figure 2 All paired measurements $(n=35)$ :

Bland-Altman method.

the NCCOM3-R7 overestimated the dye dilution cardiac output by more than 4.0 (3.2) $1 / \mathrm{min}$. In one case it underestimated dye dilution cardiac output by $0.3 \mathrm{l} / \mathrm{min}$.

\section{ALL CARDIAC OUTPUT VALUES}

The Pearson's correlation coefficient of all 35 paired measurements was 0.48 (fig 1). Individual coefficients ranged from -0.01 to 0.81 (table 1). The mean of all impedance cardiac output measurements was 10.2 (3.5) $1 / \mathrm{min}$, which was higher $(\mathrm{p}<0.001)$ than the mean dye dilution cardiac output: 7.4 (1.7) $1 / \mathrm{min}$. The mean discrepancy between the two methods was $3.3(2.6) 1 / \mathrm{min}$, and the mean bias $-2.9 \mathrm{l} / \mathrm{min}$, with limits of agreement of -9.0 and $3.2 \mathrm{l} / \mathrm{min}$ (fig 2). The Bland-Altman plot of these data suggests that at higher levels of cardiac output the impedance method progressively overestimated dye dilution values and that the agreement between the two methods is closest at cardiac output values of about 6 to $7 \mathrm{l} / \mathrm{min}$.

CARDIAC OUTPUT VALUES DURING DOPAMINE INFUSION

In subjects 3 and 5 dye dilution cardiac output did not rise above $8.0 \mathrm{l} / \mathrm{min}$, even with the highest dopamine dose $(6 \mu \mathrm{g} / \mathrm{kg} / \mathrm{min})$. Pear-

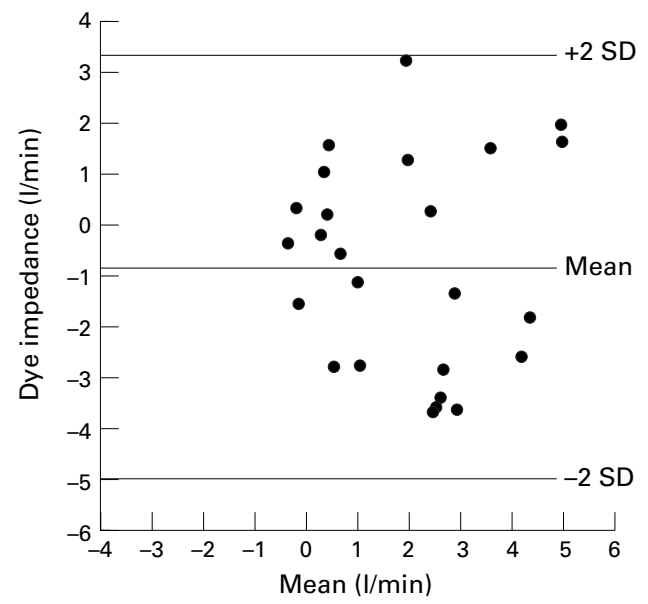

Figure 3 Changes in cardiac output during dopamine infusion $(n=25)$ : Bland-Altman method.

son's correlation coefficient of all 25 paired, dopamine related measurements was 0.56 . During dopamine infusion dye dilution cardiac output was $7.7(1.8) \mathrm{l} / \mathrm{min} v 10.5$ (3.6) $1 / \mathrm{min}$ for the NCCOM3-R7 ( $<<0.001)$. In 20 out of 25 dopamine related measurements there was a rise in dye dilution cardiac output compared with basal values (range 0.2 to $5.9 \mathrm{l} / \mathrm{min}$ ). In two cases the NCCOM3-R7 showed a decline in cardiac output where there was actually a rise in dye dilution cardiac output, while in three cases the NCCOM3-R7 showed a rise in cardiac output where there was a decline in dye dilution cardiac output. The mean discrepancy of the relative changes in cardiac output between the two methods was $1.8 \mathrm{1} / \mathrm{min}$, and the mean bias $-0.8 \mathrm{l} / \mathrm{min}$, with limits of agreement of -4.9 and $3.3 \mathrm{l} / \mathrm{min}$ (fig 3 ).

\section{Discussion}

To the best of our knowledge, this report is the first study comparing cardiac output measurements of the NCCOM3-R7 impedance cardiograph with the dye dilution technique. The NCCOM3-R7 impedance cardiograph has several important advantages compared with the dye dilution method: it is non-invasive, easy to use, cost-effective, and it allows continuous monitoring. As was decided in the meeting of a working party of the European Society of Cardiology in 1990 in Beerse (Belgium), however, the gold standard for assessing cardiac output still is the dye dilution method, and newer (non-invasive) methods for measuring cardiac output should be compared with this technique. According to our data the NCCOM3-R7 can overestimate dye dilution cardiac output by 9 (!) litres or underestimate it by more than 3 litres. This lack of agreement is unacceptable, both for clinical practice and for research purposes. Also, the relative change in cardiac output induced by intravenous dopamine infusion could not be adequately followed by the NCCOM3-R7. The discrepancies with the dye dilution method were too large to be tolerable.

Since the first commercial NCCOM became available from BoMed Medical Manufacturing in 1982, several comparative studies have been published. These cannot always be compared 
easily. A recent review summarised all available clinical studies. ${ }^{43}$ Overall, 34 studies were reviewed including 708 patients in 13 different patient categories. Most of these studies used earlier versions of the NCCOM3-R7. The NCCOM3-R7 was mostly compared with the thermodilution technique, and the majority of studies used a correlation coefficient to compare methods. Only a few studies applied the appropriate technique for analysing agreement between two methods: bias plot analysis and calculation of mean differences. ${ }^{44}$ Despite the difficulty in comparing the various studies, it was concluded that estimating cardiac output with impedance cardiography remains controversial. Only two studies compared the NCCOM3 (both using the NCCOM3-R6) with dye dilution. ${ }^{29}{ }^{39}$ The study by O'Connell et al in children $^{39}$ also showed poor agreement between the two methods. Nevertheless, by using a modification, the investigators were able to improve the agreement. Thomas ${ }^{29} \mathrm{did}$ not apply the standard procedure for the assessment of dye dilution cardiac output, but rather used the less reliable earpiece densitometer. Like us, he studied five healthy volunteers and found an acceptable mean bias of $-0.61 / \mathrm{min}$. Except for the difference in methodology, a possible explanation for the discrepancy between his results and ours is the fact that in the study by Thomas resting cardiac output averaged $7.2 \mathrm{l} / \mathrm{min}$, which, according to our data, is close at the point where dye dilution and impedance cardiography correlate best. Nevertheless, with higher cardiac output levels induced by exercise, his impedance data may also differ from -4 to $+5 \mathrm{l} / \mathrm{min}$ from the dye values.

We can only speculate about the reasons why impedance cardiography fared so badly. However, the implicit assumptions related to this method have not been sufficiently tested in experimental models. The specific resistivity of blood may not be constant, and placement of electrodes may be more critical than has been thought. Finally, the Sramek-Bernstein approach probably causes specific problems, as we found the correlation between dye dilution and impedance cardiography according to Kubicek $e t a l^{2}$ to be much better. ${ }^{3}$

In conclusion, we found that in healthy volunteers impedance cardiography with the NCCOM3-R7 is inadequate for assessing cardiac output when compared with the dye dilution method.

1 Bernstein DP. Noninvasive cardiac output measurement. In: Shoemaker WC, Ayres S, Grenvik A, Holbrook PR, Thompson WL, eds. Textbook of critical care medicine. Thompson WL, eds. Textbook of crit

2 Kubicek WG, Karnegis JN, Patterson RP, Witsoe DA, Mattson RH. Development and evaluation of an impedance cardiac output system. Aerospace Med 1966;37:120812.

3 White SW, Quail AW, de Leeuw PW, Traugott FM, Brown WJ, Porges WL, et al. Impedance cardiography for cardiac output measurement: An evaluation of accuracy and limitations. Eur Heart f 1990;11(suppl I):79-92.

4 Sramek BB, Rose DM, Miyamoto A. Stroke volume equation with a linear base impedance model and its accuracy, as compared to thermodilution and magnetic flowmracy, as compared to thermodilution and magnetic flowmInternational Conference on Electrical Bioimpedance, Zadar, International Conference
Yugoslavia, 1983:38-41.
5 Bernstein DP. A new stroke volume equation for thoracic electrical bioimpedance: theory and rationale. Crit Care Med 1986;14:904-9.

6 Appel PL, Kram HB, Mackabee J, Fleming AW, Shoemaker WC. Comparison of measurements of cardiac output by bioimpedance and thermodilution in severely ill surgical patients. Crit Care Med 1986;14:933-5.

7 Appel PL, Bernstein DP, Curtis DL, Shoemaker WC, Kram $\mathrm{HB}$, Fleming AW. Evaluation of a continuous, on-line realtime noninvasive cardiac output and ejection fraction measurements by electrical bioimpedance in critically ill patients [abstract]. Crit Care Med 1987;15:364.

8 Balestra B, Malacrida R, Leonardi L, Suter P, Marone C. Esophageal electrodes allow precise assessment of cardiac output by bioimpedance. Crit Care Med 1986;14:933-5.

9 Belardinelli R, Ciampani N, Costantini C, Blandini A, Purcaro A. Comparison of impedance cardiography with thermodilution and direct Fick methods for noninvasive measurement of stroke volume and cardiac output during incremental exercise in patients with ischemic cardiomyopathy. Am f Cardiol 1996;77:1293-301.

10 Bernstein DP. Continuous noninvasive real-time monitoring of stroke volume and cardiac output by thoracic electrical bioimpedance. Crit Care Med 1986;14:898-901.

11 Castor G, Molter G, Helms J, Niedermark I, Altmayer P. Determination of cardiac output during positive endexpiratory pressure: noninvasive electrical bioimpedance compared with standard thermodilution. Crit Care Med 1990;18:544-6.

12 Clancy TV, Norman K, Reynolds R, Covington D, Maxwell JG. Cardiac output measurement in critical care patients: thoracic electrical bioimpedance versus thermodilution. $\mathcal{f}$ Trauma 1991;31:1116-21.

13 Easterling TR, Benedetti TJ, Carlson KL, Watts DH. Measurement of cardiac output in pregnancy by thermodilution and impedance techniques. Br f Obstet Gynaecol 1989;96:67-9.

14 Gotshall RW, Wood VC, Miles DS. Comparison of two impedance cardiographic techniques for measuring cardiac output in critically ill patients. Crit Care Med 1989;17:80611 .

15 Introna RPS, Pruett JK, Crumrine RC, Cuadrado AR. Use of transthoracic bioimpedance to determine cardiac output in pediatric patients. Crit Care Med 1988;16:1101-5.

16 Jewkes C, Sear JW, Verhoeff F, Sanders DJ, Foëx P. Non-invasive measurement of cardiac output by thoracic electrical bioimpedance: a study of reproducibility and comparison with thermodilution. Br f Anaesth 1991;67: 788-94.

17 Masaki DI, Greenspoon JS, Ouzounian JG. Measurement of cardiac output in pregnancy by thoracic electrical bioimcardiac output in pregnancy by thoracic electrical bioim-
pedance and thermodilution. Am 7 Obstet Gynecol 1989; 161: $680-4$.

18 Northridge DB, Findlay IN, Wilson J, Henderson E, Dargie HJ. Non-invasive determination of cardiac output by Doppler echocardiography and electrical bioimpedance. $\mathrm{Br}$ Heart f 1990;63:93-7.

19 Pepke-Zaba J, Higenbottam TW, Dinh Xuan AT, Scott JP, English TAH, Wallwork J. Validation of impedance cardiography measurements of cardiac output during limited exercise in heart transplant recipients. Transplant Int 1990;3:108-12.

20 Preiser JC, Daper A, Parquier J-N, Contempré B, Vincent J-L. Transthoracic electrical bioimpedance versus thermodilution technique for cardiac output measurement during mechanical ventilation. Intensive Care Med 1989;15: 221-3.

21 Sageman WS, Amundson DE. Thoracic electrical bioimpedance measurement of cardiac output in postaortocoropedance measurement of cardiac output in postaortoco

22 Salandin V, Zussa C, Risica G, Michielon P, Paccagnella A, Cipolotti G, et al. Comparison of cardiac output estimation by thoracic electrical bioimpedance, thermodilution, and Fick methods. Crit Care Med 1988;16:1157-8

23 Shimizu H, Seki S, Mizuguchi A, Tsuchida H, Watanabe $H$, Namiki A. Cardiac output monitoring by impedance cardiography in cardiac surgery [English abstract]. Masui 1990; 39:508-12.

24 Shoemaker WC, Appel PL, Kram HB, Nathan RC, Thompson JL. Multicomponent noninvasive physiologic monitoring of circulatory function. Crit Care Med 1988;16: 482-90.

25 Silke B. Non-invasive determination of cardiac output by Doppler echocardiography and electrical bioimpedance Doppler echocardiography and elect

26 Spahn DR, Schmid ER, Tornic M, Jenni R, von Segesser L, Turina $\mathrm{M}$, et al. Noninvasive versus invasive assessment of cardiac output after cardiac surgery: clinical validation. $\mathcal{F}$ Cardiothorac Anesth 1990;4:46-59.

27 Spinale FG, Reines HD, Crawford FA. Comparison of bioimpedance and thermodilution methods for determining cardiac output: experimental and clinical studies. Ann Thorac Surg 1988;45:421-5.

28 Thomas AN, Ryan J, Doran BRH, Pollard BJ. Bioimpedance versus thermodilution cardiac output measurement: the Bomed NCCOM3 after coronary bypass surgery. Intensive Care Med 1991;17:383-6.

29 Thomas SHL. Impedance cardiography using the SramekBernstein method: accuracy and variability at rest and during exercise. Br F Clin Pharmacol 1992;34:467-76.

30 Wong DH, Tremper KK, Stemmer EA, O'Connor D, Wilbur S, Zaccari J, et al. Noninvasive cardiac output:
simultaneous comparison of two different methods with thermodilution. Anesthesiology 1990;72:784-92. 
31 Woo MA, Hamilton M, Stevenson LW, Vredevoe DL. Comparison of thermodilution and transthoracic electrical bio-
impedance cardiac outputs. Heart Lung 1991;20:357-62.

impedance cardiac outputs. Heart Lung 1991;20:357-62.
32 Yakimets J, Jensen L. Evaluation of impedance cardiography: comparison of NCCOM3-R7 with Fick and thermodilution methods. Heart Lung 1995;24:194-206.

33 Braden DS, Leatherbury L, Treiber FA, Strong WB Noninvasive assessment of cardiac output in children using impedance cardiography. Am Heart 7 1990;120:1166-72.

34 Smith SA, Russell AE, West MJ, Chalmers J. Automated non-invasive measurement of cardiac output: comparison of electrical bioimpedance and carbon dioxide rebreathing techniques. Br Heart 7 1988;59:292-8.

35 De Mey C, Enterling D. Noninvasive assessment of cardiac performance by impedance cardiography: disagreement between two equations to estimate stroke volume. Aviat Space Environ Med 1988;59:57-62.

36 Huang KC, Stoddard M, Tsueda K, Heine MF, Thomas $\mathrm{MH}$, White $\mathrm{M}$, et al. Stroke volume measurements by electrical bioimpedance and echocardiography in healthy volunteers. Crit Care Med 1990;18:1274-8.

37 Tibballs J. A comparative study of cardiac output in Tibballs J. A comparative study of cardiac output in
neonates supported by mechanical ventilation: measurement with thoracic electrical bioimpedance and pulsed Doppler ultrasound. F Pediatr 1989;114:632-5.

38 Moore R, Sansores R, Guimond V, Abboud R. Evaluation of cardiac output by thoracic electrical bioimpedance during exercise in normal subjects. Chest 1992;102:448-55.

39 O'Connell AJ, Tibballs J, Coulthard M. Improving agreement between thoracic bioimpedance and dye dilution cardiac output estimation in children. Anaesth Intensive Care 1991;19:434-40.

40 Lund-Johansen P. The dye dilution method for measurement of cardiac output. Eur Heart $\mathcal{F}$ 1990; 11(suppl I): $6-12$

41 De Leeuw PW, Birkenhäger WH. Some comments on the usefulness of measuring cardiac output by dye dilution. Eur Heart f 1990;11(suppl I): 13-16.

42 Bland JM, Altman DG. Statistical methods for assessing agreement between two methods of clinical measurement. Lancet 1986;i:307-10.

43 Jensen L, Yakimets J, Teo KK. A review of impedance cardiography. Heart Lung 1995;24:183-93.

44 Conway J. Clinical assessment of cardiac output. Eur Heart f 1990;11(suppl I): 148-50. 